\title{
Individuals with isolated congenital GH deficiency due to a GHRH receptor gene mutation appear to cope better with SARS-CoV-2 infection than controls
}

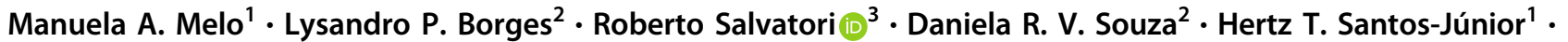 \\ José. M. de R. Neto ${ }^{2}$ Viviane C. Campos ${ }^{1}$ - Aryanne A. Santos ${ }^{2}$ Carla R. P. Oliveira ${ }^{1} \cdot$ Grazielly B. da Invenção ${ }^{2}$. \\ Vanderlan O. Batista ${ }^{1} \cdot$ Igor L. S. Matos ${ }^{2} \cdot$ Cynthia S. Barros-Oliveira $^{1} \cdot$ Kezia A. dos Santos ${ }^{2} \cdot$ Elenilde G. Santos ${ }^{1}$. \\ Nicolas A. A. Souza ${ }^{2}$ - Enaldo V. Melo ${ }^{1} \cdot$ Pamela C. Borges $^{2}$ - Saulo E. F. S. Santos ${ }^{1} \cdot$ Brenda M. de Oliveira $^{2}$. \\ Alécia A. Oliveira-Santos ${ }^{1} \cdot$ Amélia R. de Jesus $^{4} \cdot$ Manuel H. Aguiar-Oliveira ${ }^{1}$
}

Received: 7 February 2021 / Accepted: 5 April 2021 / Published online: 16 April 2021

(c) The Author(s), under exclusive licence to Springer Science+Business Media, LLC, part of Springer Nature 2021

\begin{abstract}
Purpose Several interactions exist between the GH/IGF axis and the immune system, including effects on innate immunity and humoral and cellular response. Acquired GH deficiency (GHD) has been recently proposed as a risk factor for severity of COVID-19 infections. However, acquired GHD is often associated to other factors, including pituitary tumors, surgery, radiotherapy, and additional pituitary hormones deficits and their replacements, which, together, may hinder an accurate analysis of the relationship between GHD and COVID-19. Therefore, we decided to assess the seroprevalence of SARSCoV-2 antibodies and the frequency of symptomatic cases of COVID-19 in adults subjects with untreated isolated GHD (IGHD) due to a homozygous null mutation in the GHRH receptor gene.

Methods A cross-sectional study was carried out in 27 adult IGHD subjects and 27 age- and gender-matched local controls. Interview, physical examination, bio-impedance, hematological and SARS-CoV-2 IgM and IgG antibodies were analyzed. Results There was no difference in the prevalence of positivity of anti-SARS-CoV-2 IgM and IgG antibodies between the two groups. Conversely, no IGHD individual had a previous clinical diagnosis of COVID-19 infection, while 6 control subjects did $(p=0.023)$.

Conclusion The production of anti-SARS-CoV-2 antibodies was similar between IGHD subjects due to a GHRH receptor gene mutation and controls, but the evolution to symptomatic stages of the infection and the frequency of confirmed cases was lower in IGHD subjects than in GH sufficient individuals.
\end{abstract}

Keywords GH $\cdot$ GHRH receptor $\cdot \mathrm{IGF-I} \cdot \mathrm{COVID}-19 \cdot \mathrm{SARS}-\mathrm{CoV}-2$

These authors contributed equally: Manuela A. Melo, Lysandro P. Borges

\section{Roberto Salvatori}

salvator@jhmi.edu

1 Division of Endocrinology, Health Sciences Graduate Program, Aracaju, Brazil

2 Laboratory of Biochemistry and Clinical Immunology, Aracaju, Brazil

3 Division of Endocrinology, Diabetes and Metabolism, Department of Medicine, The Johns Hopkins University School of Medicine, Baltimore, MD 21287, USA

4 Division of Immunology, Health Sciences Graduate Program Federal University of Sergipe, Aracaju 49060-100 Sergipe, Brazil

\section{Introduction}

The function of the GH/Insulin-Like Growth Factors (IGFs) system is extremely complex. It involves two circuits: one critical for body size, the somatotropic axis, including GH releasing hormone $(\mathrm{GHRH}) /$ pituitary $\mathrm{GH} /$ and circulating IGF-I; and other, the extra-pituitary GH/IGF-I and IGF-II production in several sites, more relevant for specialized body functions including immunity $[1,2]$. There is a crosstalk between the GH/IGFs system and the immune system, although its exact implications are not fully understood. These interactions may include effects on innate immunity and humoral and cellular response [3, 4]. The generation of IGF-I requires binding of GH to the GH 
receptor, a class I cytokine receptor that triggers phosphorylation of Janus Kinase 2, and activation of the transcriptional-5b gene (STAT5b) [5, 6]. Prolactin, gamma interferon and several interleukins (IL) also bind to cytokine receptors and activate the STAT family [6]. The binding of IL-2 to its receptor and the activation of STAT5b lead to the activation of $\mathrm{T}$ lymphocytes and inhibition of its apoptosis (protection against infections), and to the development and proliferation of regulatory $\mathrm{T}$ cells (attenuating autoimmunity) [7]. It is possible that local effects of GH, IGF-I, IGF-II, IGF binding proteins are more relevant for the immune system than the activity of pituitary GH and circulating IGF-I $[3,8,9]$.

The immune consequences of GH deficiency (GHD) are still debated. Although subclinical changes in laboratory parameters (such as chemotaxis and phagocytosis by granulocytes, macrophages, and natural killer cell activity) have been described in GHD, this condition does not appear to induce relevant alteration of the immune system in humans [10]. The COVID-19 pandemic, with 127 million confirmed cases and a death toll exceeding 2.7 million as of February 2021 [11], constitutes a public health emergency of international concern [12]. Male gender, old age, and obesity are, among others, known risk factors for mortality during this pandemic. As these conditions are associated with decreased GH secretion, it has been hypothesized that GHD may be a risk factor for the severity of COVID-19 [13, 14]. Acquired GHD has been proposed as a model to study the interactions between COVsID-19, GH, and immunity $[13,14]$. However, acquired GHD is often associated to several confounders such as pituitary tumors, surgery, radiotherapy, and several other pituitary hormone deficits and their replacements, which, together, may hinder an accurate analysis of the relationship between GHD and COVID-19.

We have previously described extended kindred with severe, congenital isolated GHD (IGHD) due to the c.57 $+1 \mathrm{G}>\mathrm{A}$ mutation in the GHRH receptor gene (GHRHR, OMIM n.618157) residing in Itabaianinha county, in the northeastern Brazilian state of Sergipe [15]. These subjects exhibit throughout life extremely low GH levels and very low to undetectable serum IGF-I levels [16]. They have severe short stature, visceral obesity [17], but increased insulin sensitivity [18], and normal longevity [19]. We have shown that these IGHD subjects do not exhibit increased frequency of infections or a significant alteration in humoral immune response [20]. However, they exhibit reduction of total IgG levels, smaller papule diameter after streptokinase test, and a non-significant tendency to reduced cellular response to the three combined tests: streptokinase, protein purified derived and Candida albicans antigen. These differences seem without clinical relevance in normal conditions, but may contribute to an unfavorable outcome in situations of more severe infections by extracellular pathogens [20]. Conversely, In vitro and in vivo studies in experimental models of an intracellular pathogen, Leishmania amazonensis have shown a positive effect of low serum IGF-I on this infection [21, 22]. Indeed, macrophages from the IGH subjects of Itabaianinha are less prone to Leishmania infection compared to GH sufficient controls [23].

This population represent an ideal model to study whether GHD influences the prevalence or severity of SARS-CoV-2 infections. The seroprevalence of SARS-CoV-2 antibodies in an asymptomatic population in Itabaianinha county was quite high in May 2020 (13.2\% for IgM and $10.2 \%$ for $\operatorname{IgG}$ ) [24]. Therefore, in October 2020 we measured the seroprevalence of SARS-CoV-2, as well as the frequency of confirmed cases of COVID-19 in this period in a group of asymptomatic individuals with IGHD and compared with local controls. In addition, we analyzed some demographic and clinical variables that may influence this infection.

\section{Subjects and methods}

\section{Subjects}

In a cross-sectional study, IGHD and age- and sex-matched control subjects were recruited by advertising placed in the local Dwarfs Association building, and by word of mouth among the inhabitants of Itabaianinha, a homogeneous miscegenated population in rural northeastern Brazil. Inclusion criteria for IGHD were homozygosity for the c.57 $+1 \mathrm{G} \rightarrow \mathrm{A}$ GHRHR mutation, while homozygosity for the wild-type GHRHR allele was required for the control group. Exclusion criteria were age less than 12 years, GH treatment in the past ten years, and current signs and symptoms of COVID 19, namely cough, sore throat, fever, muscle or joint pain, fatigue, or headache [25]. Presently, we are aware of 54 living IGHD individuals in this cohort [2]. With the obvious difficulties of the time of the pandemic, especially fear of contamination, we decided to study half of this number, 27 IGHD subjects. From our database of genotyped homozygous normal subjects, we randomly enrolled the first 27 controls with similar age and sex distribution to the IGHD group, living in the same household or neighborhoods. Both groups are followed in the same primary care unit by one of the authors (HTS-J). They also have direct and rapid access to tertiary medical care at the University hospital. None of the 54 IGHD living individuals was diagnosed or hospitalized for Covid 19.

Collection was accomplished in three successive days in October 2020, with all the standard safety procedures. The Federal University of Sergipe Institutional Review Board approved these studies, and all subjects gave informed consent. 


\section{Interview, physical examination, bio-impedance, and laboratory assessment}

The subjects were first submitted to an interview including demographic data; previous signs and symptoms of COVID-19 from May to October 2010 registered in medical files, and with COVID-19 diagnosis confirmed by real-time reverse transcription polymerase chain reaction (qRT-PCR) [21]. Risk factors for COVID-19 complications, such as cardiovascular disease, diabetes, arterial hypertension, and dyslipidemia were recorded. Body weight and height were measured, and body mass index was calculated. Blood pressure was calculated by the average of three measurements obtained in the left arm after 10 minutes of rest in the sitting position using a mercury sphygmomanometer with a cuff appropriate for the size of the arm. Bioimpedance was performed using the HBF-514C Full Body Digital Bioimpedance Scale, Omron Health Care Co., Ltd, Kyoto, 617-0002, Japan. Blood was collected for blood count (red, white blood cells and platelets) and for $\operatorname{IgM}$ and $\operatorname{IgG}$ measurements performed by immunofluorescence assays at the Laboratory of Biochemistry and Clinical Immunology (LaBiC-Imm) of the Federal University of Sergipe (UFS). Anti-SARS-CoV-2 IgM and IgG antibodies were detected in sera using an in vitro diagnostic test system based on lateral flow sandwich detection immunofluorescence technology (Ichroma2 ${ }^{\mathrm{TM}}$ COVID-19 $\mathrm{Ab}$ in conjunction with an Ichroma $^{\mathrm{TM}}$ II Reader, Boditech Med Inc., South Korea). The immunofluorescence method applied showed a sensitivity of $95.8 \%$ and a specificity of $97 \%$. A validation study was performed by qRT-PCR, which confirmed 60 cases of COVID-19, and 60 negative subjects [24].

\section{Statistical analysis}

The continuous variables were expressed as mean (standard deviation) and were compared by Student's $t$ test. Categorical variables were compared by the Fisher's exact test. We also provide the $95 \%$ confidence interval $(95 \% \mathrm{CI})$ for the difference of means in each comparison of the continuous variables [26]. The 95\% CI that does not contain zero implies a significant difference between the groups. The effect size was estimated by the Cohen's test in small $(0.20$ to 0.30$)$, medium $(0.40$ to 0.7$)$ and large $(\geq 0.80)$. The software IBM SPSS ${ }^{\circledR}$ Statistics version 20 was used, and the statistical significance was set at $p<0.05$.

\section{Results}

There was no significant difference in gender (12 females in IGHD and 17 in controls, $p=0.137$ ), number of diabetics (three IGHD, four in control, $p=0.698$ ), dyslipidemia (three in IGHD and two in control, $p=1$ ), arterial hypertension (five in IGHD and seven in controls $p=0.417$ ), cardiac disease (three in IGHD and one in controls, $p=$ 0.611 ), and respiratory disease (one in IGHD and thee in controls, $p=0.341$ ). Table 1 shows the comparison of the anthropometric, hematological, and immunological data between the two groups. As expected, height, weight, body surface, and lean mass were lower in IGHD $(p<0.0001$ in all cases). Fat mass $\%$ had a trend to being higher ( $p=$ 0.07 ), and visceral fat mass was higher in IGHD group $(p=0.006)$. There were also no differences in BMI, blood pressure, and in any of the hematology data. Similarly, there was no difference in the prevalence of Anti-SARSCoV-2 IgM and IgG antibodies between the two groups. However, no IGHD individual had a history of symptoms or diagnosis of COVID-19 infection, while 6 control subjects had it $(p=0.023)$, with a mean difference of $22.8 \%$, $95 \%$ CI (4.7-38.1\%), and an effect size of 0.535. Of the six subjects who had symptoms of Covid disease, four were positive for both IgM and IgG, one was positive for IgG and the other for IgM.

\section{Discussion}

This study suggests an unexpected advantage of an endocrine genetic defect causing IGHD [23]. IGHD individuals with severe short stature and extremely low GH and undetectable IGF-I levels [16], in an environment with a high transmission rate of SARS-CoV-2, appear to cope better with this infection than GH sufficient controls. It is noteworthy that the positivity of anti-SARS-CoV-2 IgM and $\mathrm{IgG}$ antibodies was similar between IGHD and controls, and about three times greater than that recorded, with the same method, in Itabaianinha five months earlier, indicating an acceleration of the pandemic [24]. Despite this acceleration, in this period no IGHD subject had a clinical diagnosis of COVID-19, or reported symptoms that would be consistent with it, while six people had it in the control group. No differences in age, sex and associated comorbidities were identified between the groups that are known to influence the clinical outcome of SARS-CoV-2 infection. Similarly, no hematological data was different between the two groups. Mask use, social distancing, and personal hygiene are likely similar in the two groups, because most IGHD and controls live in the same house or neighborhood.

One variable that may have an impact in the apparent protection against the COVID-19 is stature. Although most people believe that being taller is a sign of higher social status and privilege, shorter, smaller bodies have numerous advantages in terms of health and longevity. With adequate nutrition and lifestyle, and good medical care, short people are less likely to suffer from age-related chronic diseases 
Table 1 Comparison of the anthropometric, hematological, and immunological data in 27 IGHD and 27 controls

\begin{tabular}{|c|c|c|c|c|}
\hline & IGHD & Controls & $95 \% \mathrm{CI}$ & $p$ \\
\hline Age (years) & $47.0(16.5)$ & $46.9(17.1)$ & -9.0 to 9.3 & 0.974 \\
\hline Height (m) & $1.30(0.1)$ & $1.62(0.1)$ & -0.37 to -0.26 & $<0.0001$ \\
\hline Weight $(\mathrm{kg})$ & $43.8(10.2)$ & $67.4(10.6)$ & -29.5 to -17.7 & $<0.0001$ \\
\hline Body surface $\left(\mathrm{m}^{2}\right)$ & $1.21(0.13)$ & $1.71(0.18)$ & -0.59 to -0.42 & $<0.0001$ \\
\hline BMI $\left(\mathrm{kg} / \mathrm{m}^{2}\right)$ & $24.5(7.3)$ & $25.6(3.3)$ & -4.45 to 2.19 & 0.480 \\
\hline Diastolic BP (mmHg) & $65.2(11.7)$ & $69.5(10.2)$ & -10.69 to 2.14 & 0.186 \\
\hline Systolic BP (mmHg) & $119.2(23.1)$ & $120.3(21.8)$ & -14.16 to 11.9 & 0.862 \\
\hline Lean mass (kg) & $26.7(9.7)$ & $34.0(7.48)$ & -14.1 to 11.8 & 0.028 \\
\hline Body fat (\%) & $34.8(13.1)$ & $26.6(11.4)$ & -0.64 to 16.9 & 0.068 \\
\hline Visceral fat $(\mathrm{kg})$ & $10.7(4.4)$ & $7,1(2.5)$ & 1.1 to 6.1 & 0.006 \\
\hline Red blood cells $\left(10^{6} / \mathrm{mm}^{3}\right)$ & $4.7(0.4)$ & $4.6(0.5)$ & -0.22 to 0.37 & 0.597 \\
\hline Platelets $\left(10^{3} / \mathrm{mm}^{3}\right)$ & $275(55.3)$ & $259.8(66.5)$ & -23.0 to 53.4 & 0.426 \\
\hline White blood cells $\left(10^{3} / \mathrm{mm}^{3}\right)$ & $8.1(2.0)$ & $7.1(2.6)$ & -0.45 to 2.47 & 0.171 \\
\hline Hemoglobin $(\mathrm{g} / \mathrm{dL})$ & $13.8(1.2)$ & $13.4(1.1)$ & -0.4 to 1.03 & 0.378 \\
\hline Hematocrit $(\%)$ & $41.2(3.5)$ & $40(3.6)$ & -1.05 to 3.4 & 0.295 \\
\hline Neutrophils (number/mm³ ${ }^{3}$ ) & $4866(1755)$ & $4039(1651)$ & -236 to 1889 & 0.124 \\
\hline Lymphocytes (number $/ \mathrm{mm}^{3}$ ) & $2302(652)$ & $2179(1001)$ & -403 to 651 & 0.638 \\
\hline Monocytes (number/mm³) & $560(253)$ & $570(304)$ & -184 to 165 & 0.913 \\
\hline Eosinophils (number $/ \mathrm{mm}^{3}$ ) & $393(449)$ & $261(256)$ & -96.5 to 360.3 & 0.250 \\
\hline Basophils (number/mm³) & $4.8(6.7)$ & $3.3(4.8)$ & -2.2 to 5.1 & 0.437 \\
\hline Positive IgM only $n(\%)$ & $5(18.5)$ & $4(14.8)$ & -15 to 22.2 & 0.720 \\
\hline Positive IgG only $n(\%)$ & $1(3.7)$ & $5(18.5)$ & -5.2 to 34.8 & 0.190 \\
\hline Positive $\operatorname{IgM}$ and $\operatorname{IgG} n(\%)$ & $6(22.2)$ & $5(18.5)$ & -21.5 to 28.9 & 0.735 \\
\hline COVID-19diagnosis $n(\%)$ & $0(0)$ & $6(22.2)$ & $4.7-38.1$ & 0.023 \\
\hline
\end{tabular}

The continuous variables were analyzed by Student $t$ test and the categorical data by the Fisher exact test. 95\% CI: $95 \%$ confidence interval for the difference of means and more likely to reach advanced age [27]. Several biological factors can explain these benefits, including reduced cell replication, lower DNA damage and reduced cancer incidence, higher sex hormone binding globulin, lower IGFI, IGF binding protein, and insulin [27]. Several of these findings are present in the Itabaianinha IGHD subjects $[1,2]$. The results of a survey of 2000 people in the UK and the USA indicated that height above $1.8 \mathrm{~m}$ is a significant predictor of risk SARS-CoV-2 infection for men suggesting that downward droplet transmission may be less important than aerosol transmission https://www.medrxiv.org/content/ 10.1101/2020.07.13.20152819v1. Because the positivity of Anti-SARS-CoV-2 antibodies was similar between the IGHD and controls, we can infer that stature, in the studied range, did not influence the rate of infection with SARSCoV-2. However, short stature may be a protective factor through a reduced viral load, which could influence the lower rates of COVID-19 symptoms.

The second aspect that can have an impact in our findings is body composition. IGHD subjects have reduced lean mass and higher visceral fat mass than controls [17, 28]. Obesity is a strong risk factor for the severity of COVID19 disease. The reasons of this increased risk may involve mechanical alterations of the airways and lung parenchyma, systemic and airway inflammatory, and metabolic dysfunction [29, 30]. It is known that visceral obesity characterizes a chronic low-grade inflammation, with abnormal secretion of adipokines and cytokines like interleukin 6 (IL6), TNF- $\alpha$ and interferon, as it has been described in H1N1 influenza and other infections, as well as in asthma [31, 32]. This inflammatory pattern could cause an impaired immune response to the infection by SARS-CoV-2. Our data suggest that visceral obesity in the context of IGHD, does not confer a greater infectious risk, similarly to the previously described lack of risk of metabolic $[17,18]$ and cardiovascular disease $[33,34]$. This surprising association of metabolic and immune benefits with increased visceral adiposity is also shown in GH resistant (GHRKO) mice, that exhibit favorable changes in visceral fat secretory activity, like an increase in adiponectin $[35,36]$, also present in our IGHD subjects [37]. Accordingly, the visceral fat of GHRKO mice has reduced infiltration of inflammatory cells and therefore less intense inflammatory potential [35]. Interestingly, hyperactivation of the mechanistic target of rapamycin (mTOR) pathway seems a possible contributor to the higher rate and severity of COVID-19 in obese patients [38], 
enhancing the virus entry into host cells, through its human angiotensin-converting enzyme 2 receptor [39]. Some evidence suggests that the mTOR pathway is down-regulated in $\mathrm{GH}$ deficient mice and humans [1], which can exert a protective effect against a deleterious progression of the SARS-CoV-2 infection in the IGHD subjects.

In interpreting these data and in considering a wide application on the effects of GHD on the clinical manifestations of SARS-CoV-2 infection, one should consider many differences between our subjects and patients with acquired GHD. In addition to the previously mentioned differences related to acquired GHD (often seen in panhypopituitarism with history of surgery and/or radiation), one important aspect is the vitamin D status. Acquired GHD patients often exhibit vitamin D deficiency, a condition that has been linked to an increased risk of systemic infections and to immune response impairment [40]. Vitamin D insufficiency in acquired GHD may reflect reduced sun light exposure, sedentary lifestyle, co-morbidities, and drug use (such as anti-convulsant). Conversely, vitamin D deficiency it is not found in quite active IGHD subjects from Itabaianinha, who often work outdoor under direct sun exposure [41].

Our work has some limitations. First, the apparently small number of 27 individuals per group. However, with the effect size of 0.535 in the diagnosis of COVID-19, estimating a power of 0.8 with $\alpha$ of 0.05 , we calculated that 20-30 individuals in each group would be needed, making the number appropriate. Second, in the very dynamic process of an expanding the pandemic, we carried out our study in a specific period, without longitudinal data. However, the two groups were studied in the same week, allowing for appropriate comparison. Thirdly, these results were obtained in a group with congenital IGHD, due to a particular mutation in the GHRH receptor gene, which is different from most individuals with GHD in clinical practice.

In conclusion, subjects with congenital untreated IGHD due to a GHRH receptor gene mutation appear to cope better with SARS-2-coV-2 infection than GH sufficient controls, with reduced risk of progression to symptomatic stages, suggesting a protective effect on the progression of the infection.

Acknowledgements The authors thank the Associação do Crescimento Físico e Humano de Itabaianinha, for assistance.

\section{Compliance with ethical standards}

Conflict of interest R.S. serves on Novordisk Advisory Board. The other authors declare no competing interests.

Ethical approval All procedures performed in studies involving human participants were in accordance with the ethical standards of the institutional and national research committee and with the 1964
Helsinki declaration and its later amendments or comparable ethical standards.

Publisher's note Springer Nature remains neutral with regard to jurisdictional claims in published maps and institutional affiliations.

\section{References}

1. M.H. Aguiar-Oliveira, A. Bartke, Growth hormone deficiency: health and longevity. Endocr. Rev. 40(2), 575-601 (2019)

2. Aguiar-Oliveira, M.H., Salvatori, R. Disruption of the GHRH receptor and its impact on children and adults: the Itabaianinha syndrome. Rev. Endocr. Metab. Disord. (2020). https://doi.org/10. 1007/s11154-020-09591-4. PMID: 32935264

3. S.C.V. Buul-Offers, R. Kooijman, The role of growth hormone and insulin-like growth factors in the immune system. Cell Mol. Life Sci. 54(10), 1083-1094 (1998)

4. G. Bodart, K. Farhat, C. Charlet-Renard, R. Salvatori, V. Geenen, H. Martens, The somatotrope growth hormone releasing hormone/ growth hormone/insulin-like growth factor-1 axis in immunoregulation and immunosenescence. Front. Horm. Res. 48, 147-159 (2017)

5. E.M. Kofoed, V. Hwa, B. Little, K.A. Woods, C.K. Buckway, J. Tsubaki, K.L. Pratt, L. Bezrodnik, H. Jasper, A. Tepper, J.J. Heinrich, R.G. Rosenfeld, Growth-hormone insensitivity associated with a STAT-5b mutation. N. Engl. J. Med. 349(12), 1139-1147 (2003)

6. V. Hwa, STAT5B deficiency: Impacts on human growth and immunity. Growth Horm. IGF Res. 28, 16-20 (2016)

7. J.-L. Casanova, S.M. Holland, L.D. Notarangelo, Inborn errors of human JAKs and STATs. Immunity 36(4), 515-528 (2012)

8. C.J. Auernhammer, C. Fottner, D. Engelhardt, M. Bidlingmaier, C.J. Strasburger, M.M. Weber, Differential regulation of insulinlike growth factor-(IGF)I and IGF-binding protein (IGFBP) secretion by human peripheral blood mononuclear cells. Horm. Res. Paed. 57(1-2), 15-21 (2002)

9. D. Oberlin, C. Fellbaum, E. Eppler, Insulin-like growth factor I messenger RNA and protein are expressed in the human lymph node and distinctly confined to subtypes of macrophages, antigenpresenting cells, lymphocytes and endothelial cells. Immunology 128(3), 342-350 (2009)

10. B. Velkeniers, Z. Dogusan, F. Naessens, R. Hooghe, E.L. Hooghe-Peters, Prolactin, growth hormone and the immune system in humans. Cell Mol. Life Sci. 54, 1102-1108 (1998)

11. The Worldometer. COVID-19 CORONAVIRUS PANDEMIC. (2021). https://www.worldometers.info/coronavirus/. Accessed 27 Mar 2021

12. World Health Organization. Statement on the second meeting of the International Health Regulations Emergency Committee regarding the outbreak of novel coronavirus (2019-nCoV). (2020). https://www.who.int/news-room/detail/23-01-2020-statement-onthe-meeting-of-the-internationalhealth-regulations-(2005)emergency-committee-regarding-theoutbreak-of-novel-corona virus-(2019-ncov)

13. C. Lubrano, D. Masi, R. Risi, A. Balena, M. Watanabe, S. Mariani, L. Gnessi, Is growth hormone insufficiency the missing link between obesity, male gender, age and COVID-19 severity? Obes. Res. J. 28(11), 2038-2039 (2020)

14. Yuen, K.C.J. Growth hormone deficiency, acromegaly, and COVID-19: transitioning from media reports to knowledge and a growth hormone hypothesis. Growth Horm. IGF Res. (2020). https://doi.org/10.1016/j.ghir.2020.101363. PMID: 33221709

15. R. Salvatori, C.Y. Hayashida, M.H. Aguiar-Oliveira, J.A. Phillips, A.H.O. Souza, R.G. Gondo, S.P.A. Toledo, M.M. Conceição, M. 
Prince, H.G. Maheshwari, G. Baumann, M.A. Levine, Familial Dwarfism due to a novel mutation of the growth hormonereleasing hormone receptor gene. J. Clin. Endocrinol. Metab. 84 (3), 917-923 (1999)

16. M.H. Aguiar-Oliveira, M.S. Gill, E.S.A. Barretto, M.R.S. Alcântara, F. Miraki-Moud, C.A. Menezes, A.H.O. Souza, C.E. Martinelli, F.A. Pereira, R. Salvatori, M.A. Levine, S.M. Shalet, C. Camacho-Hubner, P.E. Clayton, Effect of severe growth hormone $(\mathrm{GH})$ deficiency due to a mutation in the GH-Releasing Hormone Receptor on Insulin-like Growth Factors (IGFs), IGF-Binding Proteins, and ternary complex formation throughout life. J. Clin. Endocrinol. Metab. 84(11), 4118-4126 (1999)

17. E. Gomes-Santos, R. Salvatori, T.O. Ferrão, C.R.P. Oliveira, R.D. C.A. Diniz, J.A.M. Santana, F.A. Pereira, R.A.A. Barbosa, A.H. O. Souza, E.V. Melo, C.C. Epitácio-Pereira, A.A. Oliveira-Santos, I.A.S. Oliveira, J.A. Machado, F.J. Santana-Júnior, J.A.S. BarretoFilho, M.H. Aguiar-Oliveira, Increased visceral adiposity and cortisol to cortisone ratio in adults with congenital lifetime isolated GH deficiency. J. Clin. Endocrinol. Metab. 99(9), 3285-3289 (2014)

18. C.R.P. Oliveira, R. Salvatori, J.A.S. Barreto-Filho, I.E.S. Rocha, A. Mari, R.M.C. Pereira, V.C. Campos, M. Menezes, E. Gomes, R.A. Meneguz-Moreno, V.P. Araújo, N.T.F. Leite, A.C. NascimentoJunior, M.I.T. Farias, T.A.R. Viscente, R.D.C. Araújo, E.V. Melo, M.H. Aguiar-Oliveira, Insulin sensitivity and $\beta$-cell function in adults with lifetime, untreated isolated growth hormone deficiency. J. Clin. Endocrinol. Metab. 97(3), 1013-1019 (2012)

19. M.H. Aguiar-Oliveira, F.T. Oliveira, R.M.C. Pereira, C.R.P. Oliveira, A. Blackford, E.H.O. Valença, E.G. Santos, M.B. GoisJunior, R.A. Meneguz-Moreno, V.P. Araujo, L.A. Oliveira-Neto, R.P. Almeida, M.A. Santos, N.T. Farias, D.C.R. Silveira, G.W. Cabral, F.R. Calazans, J.D. Seabra, T.F. Lopes, E.O. Rodrigues, L.A. Porto, I.P. Oliveira, E. Melo, M. Martari, R. Salvatori, Longevity in untreated congenital growth hormone deficiency due to a homozygous mutation in the GHRH receptor gene. J. Clin. Endocrinol. Metab. 95(2), 714-721 (2010)

20. V.C. Campos, M.R. Barrios, R. Salvatori, R.P. Almeida, E.V. Melo, A.C.S. Nascimento, A.R. Jesus, M.H. Aguiar-Oliveira, Infectious diseases and immunological responses in adult subjects with lifetime untreated, congenital GH deficiency. Endocrine $\mathbf{5 4}$ (1), 182-190 (2016)

21. H. Goto, C.M.C. Gomes, C.E.P. Corbett, H.P. Monteiro, M. Gidlund, Insulin-like growth factor I is a growth-promoting factor for Leishmania promastigotes and amastigotes. Proc. Nat. Acad. Sci. USA 95(22), 13211-13216 (1998)

22. Vendrame, C.M.V., Carvalho, M.D.T., Tempone, A.G., Goto, H. Insulin-like growth factor-I induces arginase activity in Leishmania amazonensis amastigote-infected macrophages through a cytokine-independent mechanism. Mediators Inflamm. (2014). https://doi.org/10.1155/2014/475919. ID: 475919

23. Barrios, M.R., Campos, V.C., Peres, N.T.A., de Oliveira, L.L., Cazzaniga, R.A., Santos, M.B., Aires, M.B., Silva, R.L.L., Barreto, A., Goto, H., Almeida, R.P., Salvatori, R., Aguiar-Oliveira, M.H., Jesus, A.M.R. Macrophages from subjects with isolated GH/IGF-I deficiency due to a GHRH receptor gene mutation are less prone to infection by Leishmania amazonensis. Front. Cell Infect. Microbiol. 9(311) (2019). https://doi.org/10.3389/fcimb. 2019.00311

24. Borges, L.P., Martins, A.F., Melo, M.S., Oliveira, M.G.B., Neto, J.M.R., Dósea, M.B., Cabral. B.C.M., Menezes, R.F., Santos, A. A., Matos, I.L.S., Borges, P.C., Santos, K.A., Ribeiro, A.A., Menendez, A.I.M., Serafini, M.R., Walker, C.B., Junior, L.J.Q., Araújo, A.A.S., Souza, D.R.V. Seroprevalence of SARS-CoV-2 $\mathrm{IgM}$ and $\mathrm{IgG}$ antibodies in an asymptomatic population in Sergipe, Brazil. Rev. Panam. Salud. Publica. (2020). https://doi.org/ 10.26633/RPSP.2020.108. PMID: 33042199
25. Struyf, T., Deeks, J.J., Dinnes, J., Takwoingi, Y., Davenport, C., Leeflang, M.M.G., Spijker, R., Hooft, L., Emperador, D., Dittrich, S., Domen, J., Horn, S.R.A., Bruel, A.V. Signs and symptoms to determine if a patient presenting in primary care or hospital outpatient settings has COVID-19 disease. Cochrane Datab. (2020). https://doi.org/10.1002/14651858. CD: 013665

26. O.M. Dekkers, Why not to (over) emphasize statistical significance. Eur. J. Endocrinol. 181(3), E1-E2 (2019). https://doi. org/10.1530/EJE-19-0531

27. T.T. Samaras, How height is related to our health and longevity: a review. Nutr. Health 21(4), 247-261 (2012)

28. J.A.S. Barreto-Filho, M.R.S. Alcântara, R. Salvatori, M.A. Barreto, A.C.S. Sousa, V. Bastos, A.H. Souza, R.M.C. Pereira, P.E. Clayton, M.S. Gill, M.H. Aguiar-Oliveira, Familial isolated growth hormone deficiency is associated with increased systolic blood pressure, central obesity, and dyslipidemia. J. Clin. Endocrinol. Metab. 87(5), 2018-2023 (2002)

29. A. Simonnet, M. Chetboun, J. Poissy, V. Raverdy, J. Noulette, A. Duhamel, J. Labreuche, D. Mathieu, F. Pattou, M. Jourdain, High prevalence of obesity in severe acute respiratory syndrome coronavirus-2 (SARS-CoV-2) requiring invasive mechanical ventilation. Obesity 28(7), 1195-1199 (2020)

30. Q. Cai, F. Chen, T. Wang, F. Luo, X. Liu, Q. Wu, Q. He, Z. Wang, Y. Liu, L. Liu, J. Chen, L. Xu, Obesity and covid-19 severity in a designated hospital in Shenzhen, China. Diabetes Care 43(7), 1392-1398 (2020)

31. R. Huttunen, J. Syrjänen, Obesity and the risk and outcome of infection. Int. J. Obes. 37(3), 333-340 (2013)

32. M.C. Peters, K.W. McGrath, G.A. Hawkins, A.T. Hastie, B.D. Levy, E. Israel, B.R. Phillips, D.T. Mauger, S.A. Comhair, S.C. Erzurum, M.W. Johansson, N.N. Jarjour, A.M. Coverstone, M. Castro, F. Holguin, S.E. Wenzel, P.G. Woodruff, E.R. Bleecker, J. V. Fahy, Plasma interleukin-6 concentrations, metabolic dysfunction, and asthma severity: a cross-sectional analysis of two cohorts. Lancet Respir. Med. 4(7), 574-584 (2016)

33. J.L.M. Oliveira, C. Marques-Santos, J.A. Barreto-Filho, R.X. Filho, A.V.O. Britto, A.H.O. Souza, C.M. Prado, C.R.P. Oliveira, R.M.C. Pereira, T.A.R. Vicente, C.T. Farias, M.H. Aguiar-Oliveira, R. Salvatori, Lack of evidence of premature atherosclerosis in untreated severe isolated growth hormone $(\mathrm{GH})$ deficiency due to a GH-releasing hormone receptor mutation. J. Clin. Endocrinol. Metab. 91(6), 2093-2099 (2006)

34. U.M.M. Costa, C.R.P. Oliveira, R. Salvatori, J.A.S. BarretoFilho, V.C. Campos, F.T. Oliveira, I.E.S. Rocha, J.L.M. Oliveira, W.A. Silva, M.H. Aguiar-Oliveira, Brazilian adult individuals with untreated isolated GH deficiency do not have accelerated subclinical atherosclerosis. Endocr. Connect 5(1), 41-46 (2016)

35. M.M. Masternak, A. Bartke, F. Wang, A. Spong, A. Gesing, Y. Fang, A.B. Salmon, L.F. Hughes, T. Liberati, R. Boparai, J.J. Kopchick, R. Westbrook, Metabolic effects of intra-abdominal fat in GHRKO mice. Aging Cell 11, 73-81 (2012)

36. M.T. Bennis, A. Schneider, B. Victoria, A. Do, D.S. Wiesenborn, L. Spinel, A. Gesing, J.J. Kopchick, S.A. Siddiqi, M.M. Masternak, The role of transplanted visceral fat from the long-lived growth hormone receptor knockout mice on insulin signalling. Geroscience 39(1), 51-59 (2017)

37. C.R.P. Oliveira, R. Salvatori, R.A. Meneguz-Moreno, M.H. Aguiar-Oliveira, R.M.C. Pereira, E.H.A. Valença, V.P. Araujo, N. T. Farias, D.C.R. Silveira, J.G.H. Vieira, J.A.S. Barreto-Filho, Adipokine profile and urinary albumin excretion in isolated growth hormone deficiency. J. Clin. Endocrinol. Metab. 95(2), 693-698 (2010)

38. Bolourian, A., Mojatahedi, Z. Obesity and COVID-19: the mTOR pathway as a possible culprit. Obes. Rev. (2020). https://doi.org/ 10.1111/obr.13084. PMID: 32578354 
39. Kassir, R. Risk of COVID-19 for patients with obesity. Obes. Rev. (2020). https://doi.org/10.1111/obr.13034

40. A. Ciresi, C. Giordano, Vitamin D across growth hormone (GH) disorders: from GH deficiency to GH excess. Growth Horm. IGF Res. 33, 35-42 (2017)
41. C.S. Barros-Oliveira, R. Salvatori, J.S.S. Santos, P.F.C. Santos, A. A. Oliveira-Santos, C.G. Marinho, E.G. Santos, Â.C.G.B. Leal, V. C. Campos, N.P. Damascena, C.R.P. Oliveira, M.H. Aguiar-Oliveira, Sweat and vitamin D status in congenital, lifetime, untreated GH deficiency. Endocrine 65, 710-713 (2019) 